\title{
EXPERIMENTAL METHOD OF FATIGUE PERFORMANCE OF MASTIC ASPHALT FOR BRIDGE DECK PAVEMENT
}

\author{
GUILIAN ZOU1*, XIAONING ZHANG ${ }^{2}$, CHUNG WU ${ }^{3}$ \\ ${ }^{1,2}$ School of Civil Engineering and Transportation, \\ South China University of Technology, Wushan RD., \\ Tianhe District, Guangzhou, P.R. China \\ ${ }^{3}$ District Materials Engineer, Virginia Dept of Transportation, Suffolk, VA USA
}

Received 3 January 2019; accepted 30 July 2019

\begin{abstract}
Mastic asphalt is a type of pavement material that has good fluidity and is self-levelling at construction temperature for the bridge deck. There are highly accurate methods and indexes for evaluating fluidity and high-temperature deformation resistance for mastic asphalt-design and construction-control systems. The fatigue cracking is one of the main failure forms of bridge deck pavement. Therefore, the method used to evaluate the fatigue properties of pavement materials is also essential. The anti-deformation capability of the mastic asphalt must be increased, that results in poor fatigue performance and consequent failure of the bridge deck pavement to avoid the rutting of bridge deck pavement. In this study, a simple method is put forward for evaluating mastic asphalt fatigue performance. Impact toughness is defined as the area under the load-displacement curve of a three-point bending beam specimen under impact load to evaluate the fatigue performance
\end{abstract}

* Corresponding author. E-mail: glzhou@scut.edu.cn

Guilian ZOU (ORCID ID 0000-0002-3022-4270)

Xiaoning ZHANG (ORCID ID 0000-0003-3771-3111)

Chung WU (ORCID ID 0000-0002-3361-2973) 
of mastic asphalt. The four-point bending beam fatigue test is used to verify the rationality of the impact toughness test method. The results showed that there is a good correlation between the impacts toughness index of mastic asphalt produced under different mixing conditions and the accumulative dissipative energy and fatigue life demonstrated by the four-point bending beam test. Therefore, to evaluate the fatigue performance of mastic asphalt by impact toughness test. Fatigue performance and rut resistance are two ways to evaluate road performance of asphalt mixtures, but they are mutually restrictive. The results show that impact toughness and dynamic stability are inversely correlated. As the impact toughness increases, dynamic stability decreases. Therefore, balancing the fatigue performance and high-temperature rutting resistance of mastic asphalt in the design and quality control is very important.

Keywords: bridge deck pavement, dissipative energy, experimental method, fatigue, mastic asphalt, performance balance.

\section{Introduction}

The main structures of steel bridges are generally designed to 100 years, but the life of the steel bridge deck pavement is only about 10 15 years. Some bridge deck pavements needed to receive major rehabilitation within five years (Battista, Pfeil, \& Carvalho, 2008; Liu, Medani, Scarpas, Huurman, \& Molenaar, 2010; Medani, Huurman, Liu, Scarpas, \& Molenaar, 2007). One of the main reasons is the considerable deformation due to the flexibility of the steel bridge deck. Higher quality is required for steel deck pavement. Generally, two types of asphalt concrete materials were used in steel deck pavement, gussasphalt (GA), and mastic asphalt (MA). Gussasphalt was originally developed in 1917 in Germany and was called Guß, meaning river (Wang, Zhang, Zhu, Hao, \& Xue, 2011). Originally, it was used as waterproofing material in building construction and for pavement construction (BS 1447:1998 Specification for Mastic Asphalt (Limestone Fine Aggregate) for Roads, Footways and Pavings in Building, Published under the Authority of the Board of BSI). Gussasphalt was successfully used in steel deck pavement (such as the Oberkasseler Bridge, Mulheim Bridge, and Zoo Bridge). It was later used in steel bridge construction in Europe (France, Sweden, the Netherlands) with good performance records. It was in the United Kingdom that the asphalt concrete material for steel bridge deck was first called MA, a term based on its characteristics.

The primary difference between GA and MA is in the processes used to produce these two asphalt concrete mixes. In producing MA, the mineral filler, bitumen, and fine aggregate are fed at ambient temperature into a mixer sequentially and are then mixed for 5-6 hours. The product of the mixing, called mastic epuré (ME), is then fed into
Experimental

Method of Fatigue Performance of Mastic Asphalt for Bridge Deck Pavement 
a mixing truck (called a cooker) and mixed with a predetermined proportion of coarse aggregate to produce the final MA. For GA production, all ingredients are fed into a batch plant, are mixed for only 2 minutes, and then are dumped into the cooker for secondary mixing and transportation.

Other differences between GA and MA materials include the aggregate gradation, the mix design method, and property evaluation indexes. Despite the differences, both GA and MA contain more proportions of asphalt and fine aggregate and fewer amounts of coarse aggregate. Both flow easily and are thus self-levelling at construction temperature. The asphalt concrete mix for bridge deck generally termed MA in the study, as defined in European Union Specification BS EN 131086:2006 Bituminous Mixtures - Material Specifications - Part 6: Mastic Asphalt, Published under the Authority of the Standards Policy and Strategy Committee.

In warmer regions of China, the summer season is generally long and hot. With high traffic volume and a severe overloading problem, high-temperature performance is significant for highway and bridge pavements. Researchers studied various ways to improve the ruttingresistance property, such as increasing the content of Trinidad lake asphalt (TLA), using a harder grade of asphalt binder, or moderately pre-ageing asphalt mixtures during construction. However, the better an asphalt mixture resists rutting the worse is its ability to resist cracking. Therefore, performance indexes are needed to define the resistance to both ruttings at higher temperatures and fatigue cracking.

Rutting and fatigue cracking was observed on the same steel bridge deck pavements at many different locations in China. With the same source materials, MA mixtures, and construction methods, the question of how the two opposing distresses occur on the same pavement arises. The most likely reason is inadequate quality control during construction; The mixing temperature and time are very necessary to be monitored during MA production. Mixing time in the mixing truck vary within one and eight hours, but a long mixing time in the cooker require the use of additives to rejuvenate the MA mix. A similar situation also occurs in European countries during the construction of the bridge-deck asphalt pavement.

Tensile strain measured at the top of the wearing course of steelbridge-deck pavements sometimes exceeds $500 \mu \varepsilon$ that is much larger than is observed at the bottom of conventional asphalt pavements. Considerable strain explains why most distresses reported for orthotropic steel-bridge pavements were related to fatigue cracking of asphalt mixtures (de Jong, 2006; Jeong, Kainuma, \& Ahn, 2013; Kyung, Shin, Lee, \& Jeon, 2006; Shirahata, Akasaka, \& Iizuka, 2010). Among the 
many testing methods, the four- and five-point bending beam fatigue tests were frequently used in research to evaluate fatigue properties of asphalt mixtures (Pouget, Sauzéat, Di Benedetto, \& Olard, 2011; Way, Kaloush, Sousa, \& Zareh, 2009; Wu, 2009).

In 1993, in the United States, the Strategic Highway Research Program recommended the use of the four-point bending beam fatigue test to estimate fatigue cracking of asphalt mixtures (Yu \& Zhang, 2011). Since that time, it has become a standard test adopted by the AASHTO T321-2007 Standard Method of Test for Determining the Fatigue Life of Compacted Hot-Mix Asphalt (HMA) Subjected to Repeated Flexural Bending. Among its advantages is a high sensitivity to mixture variables, a larger proportion of test specimens were subjected to a uniform maximum stress level, and bending behaviour similar to real pavement deformation. The four-point test was used by various researchers to evaluate the fatigue performance of pavements and has become popular worldwide as a fatigue test for asphalt mixtures.

However, the four-point bending beam fatigue test requires highperforming equipment and a long testing cycle. Construction contractors and supervisory companies often lack the right conditions to carry out this type of testing, so it is necessary to study simple fatigue testing for MA design and construction quality. The impact toughness test is developed in this study, while also adopting the accepted four-point bending-beam fatigue test to verify feasibility to control MA fatigue performance.

\section{Objectives}

Impact toughness, a concept normally used in metallic materials science (Buirette \& Huez, 2010; Dilthey, Lüder, Bleck, Langenberg, \& Nagel, 2000; Tamminen, Juutilainen, \& Röning, 2010), is defined as the area underneath the load-displacement curve of a three-point bending specimen subjected to impact loading. Theoretical analyses based on fracture mechanics and energy principals along with laboratory testing (Mull, Othman, \& Mohammad, 2005; Mull, Stuart, \& Yehia, 2002; Pinho, Robinson, \& Iannucci, 2006; Zou, $\mathrm{Wu}, \& \mathrm{Xu}, 2013$ ) revealed an excellent correlation between impact toughness of asphalt mixtures and their ability to resist fatigue cracking: stated, the higher the impact-toughness value, the stronger the material. During travel on a steel bridge deck overlay, the wheel-to-overlay contact duration is very short, and traffic loading is considered an impact loading. It is therefore theoretically possible that impact toughness is used to evaluate fatigue performance for overlay material of steel bridge deck.
Experimental

Method of Fatigue

Performance

of Mastic Asphalt for Bridge Deck

Pavement 
The objectives of this study were fivefold:

- to propose a test method and an index of impact toughness;

- to verify whether the impact toughness index is applied to fatigue performance evaluation of bridge deck pavement materials by using the four-point bending beam test;

- to see whether a relationship between impact toughness and accumulated dissipative energy is established;

- to find the correlation between impact toughness and the dynamic stability (DS) for MA mixture;

- to decide what indexes to use for quality control of MA design and pavement construction to improve the performance-balance requirements for the pavement materials.

\section{Materials, sample preparation, and testing}

\subsection{Materials}

Three types of asphalt binders (Table 1) were used in preparing the MA mixtures in this study, including a conventional asphalt binder commonly used in China (Pen 60/70 binder), a natural-material asphalt binder (TLA), and a blended asphalt binder (70\% TLA, 30\% Pen 60/70). Pen $60 / 70$ indicates a penetration grade of $60 / 70$ at $25^{\circ} \mathrm{C}$.

The aggregate gradation used in MA (Standard System of Great Britain) is much finer than that used in GA. Finer aggregate gradation is generally beneficial for construction quality for steel-bridge-deck pavement. Therefore, the MA aggregate gradation and method of mix design were adopted in this research.

Table 1. Properties of asphalt binders

\begin{tabular}{|c|c|c|c|c|}
\hline Properties & Unit & Pen 60/70 & TLA & $70 \%$ TLA+30\% Pen 60/70 \\
\hline Penetration, $25^{\circ} \mathrm{C}, 100 \mathrm{~g}, 5 \mathrm{~s}$ & $0.1 \mathrm{~mm}$ & 61 & 3 & 18 \\
\hline Ring \& Ball temperature & ${ }^{\circ} \mathrm{C}$ & 49.0 & 90.0 & 65.0 \\
\hline Ductility at $15^{\circ} \mathrm{C}$ & $\mathrm{cm}$ & $>100$ & - & - \\
\hline Solubility of TCE* ${ }^{*}$ & $\%$ & 99.9 & 53.0 & 67.1 \\
\hline Flash point, $\mathrm{COC}^{\star \star}$ & ${ }^{\circ} \mathrm{C}$ & $>60$ & - & $>260$ \\
\hline Density & $\mathrm{g} / \mathrm{cm}^{3}$ & 1.036 & 1.381 & 1.277 \\
\hline Ash (mineral matter) & $\%$ & - & 36.5 & - \\
\hline
\end{tabular}

Note: ${ }^{\star}$ TCE - trichloroethene; ${ }^{* \star} \mathrm{COC}-$ Cleveland Open Cup method 
Table 2. Specified gradation of limestone fine aggregate

\begin{tabular}{lcc}
\hline \multicolumn{1}{c}{ Gradation of Fine Aggregate* } & \multicolumn{2}{c}{ Per cent by mass } \\
\cline { 2 - 3 } & Minimum & Maximum \\
\hline Retained on $2.36 \mathrm{~mm}$ & - & 2.5 \\
Passing $2.36 \mathrm{~mm}$ and retained on $600 \mu \mathrm{m}$ & 8 & 21 \\
Passing $600 \mu \mathrm{m}$ and retained on $212 \mu \mathrm{m}$ & 8 & 32 \\
Passing $212 \mu \mathrm{m}$ and retained on $75 \mu \mathrm{m}$ & 40 & 25 \\
Passing $75 \mu \mathrm{m}$ & & 56 \\
\hline
\end{tabular}

Note: *gradation determined by wet-sieving method (BS 812-103.2 Testing Aggregates - Part 103: Methods for Determination of Particle Size Distribution - Section 103.2: Sedimentation Test)

In this study, the fine aggregates consisted of natural limestone ground to the required gradations (Table 2) and were required to exhibit a minimum $\mathrm{CaCO}_{3}$ content of $80 \%$ by mass. The combined fine aggregate and asphalt binder constitutes a ME mixture.

The coarse aggregates are defined as materials retained on a $2.36 \mathrm{~mm}$ sieve in the MA mixtures. The proportion of coarse aggregate was recommended in the British specifications. For heavily stressed areas, the coarse aggregate content in MA mixtures was specified to be $45 \% \pm 10 \%$ by weight of the total mixture, and the remaining $55 \%$ consisted of ME. The soluble asphalt binder content was expected to be $14 \%-17 \%$ by weight of the ME mix; in the study, the percentage was $14.5 \%$. For this study, the limestone fine aggregate gradation, the asphalt binder content, and the specification requirements are listed in Table 3.

Table 3. Gradation of fine aggregate and the soluble asphalt-binder content

\begin{tabular}{|c|c|c|c|c|c|c|}
\hline \multirow{2}{*}{ Gradation } & \multicolumn{5}{|c|}{ Sieve size, $\mathrm{mm}$} & \multirow{2}{*}{$\begin{array}{c}\text { Soluble asphalt- } \\
\text { binder content, } \\
\%\end{array}$} \\
\hline & above 2.36 & $0.6-2.36$ & $0.212-0.6$ & $0.075-0.212$ & below 0.075 & \\
\hline $\begin{array}{l}\text { Percent by } \\
\text { weight }\end{array}$ & 0 & 16.0 & 20.0 & 23.0 & 41.0 & 14.5 \\
\hline BS 1447:1998* & $0-2.5$ & $4.0-21.0$ & $8.0-32.0$ & $8.0-25.0$ & $40.0-56.0$ & $14-17$ \\
\hline
\end{tabular}

Note: BS 1447:1998 Specification for Mastic Asphalt (Limestone Fine Aggregate) for Roads, Footways and Pavings in Building, Published under the Authority of the Board of BSI.
Experimental Method of Fatigue Performance of Mastic Asphalt for Bridge Deck Pavement 


\subsection{Preparation of mastic asphalt mixtures}

Mastic asphalt (MA) mixtures used in this project were produced using two different methods. Conventionally, MA mixtures were produced in the laboratory following processes listed below:

- A-70 bitumen and TLA were heated to $160{ }^{\circ} \mathrm{C}-170{ }^{\circ} \mathrm{C}$ in the oven and mineral fillers were prepared at ambient temperature. They were, then weighed and fed into the mixer (Figure 1). The mixer was heated by gas under controlled-temperature conditions. Inside the mixer, the agitating vanes were operated by a diesel engine. The mixtures were allowed to reach $170^{\circ} \mathrm{C}-190^{\circ} \mathrm{C}$ and were then mixed for an additional $30 \mathrm{~min}$.

- the fine aggregates, at ambient temperature, were fed into the mixer, and the entire mixture was agitated for 30 minutes after the mixing temperature reached $180^{\circ} \mathrm{C}-195^{\circ} \mathrm{C}$; the product was called ME.

- the coarse aggregates were then added into the mixer at an ambient temperature, and the mixture was agitated until after the temperature reached $190{ }^{\circ} \mathrm{C}-215{ }^{\circ} \mathrm{C}$. (the mixture was continued mixing 45 min- 120 min in this study.)

- the batch of MA produced in the laboratory weighed about $700 \mathrm{~kg}$.

The mixing time generally requires above 6 hours in the conventional mixing method. To meet the needs of large-scale bridge deck pavement, a more efficient automatic batch plant is used to produce MA. For example, the deck pavement for the Hong Kong-Zhuhai-Macao steel bridge has a scale above $500000 \mathrm{~m}^{2}$; production of the MA mixture for its pavement uses the following process. In the first step, all ingredients are fed into the

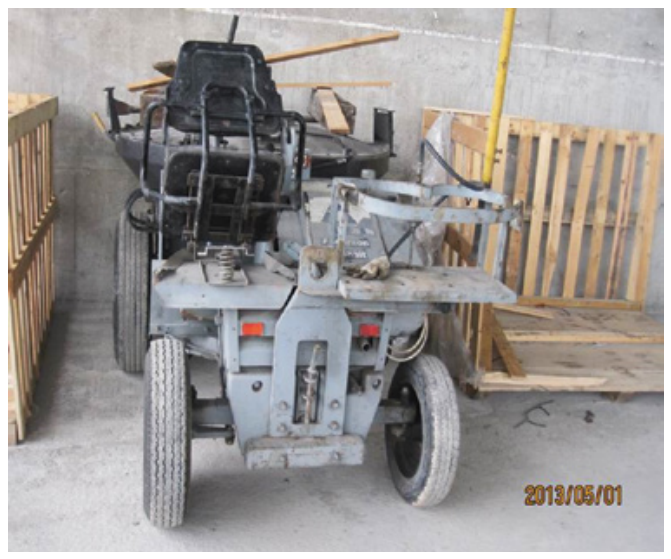

Figure 1. Conventional mixer 


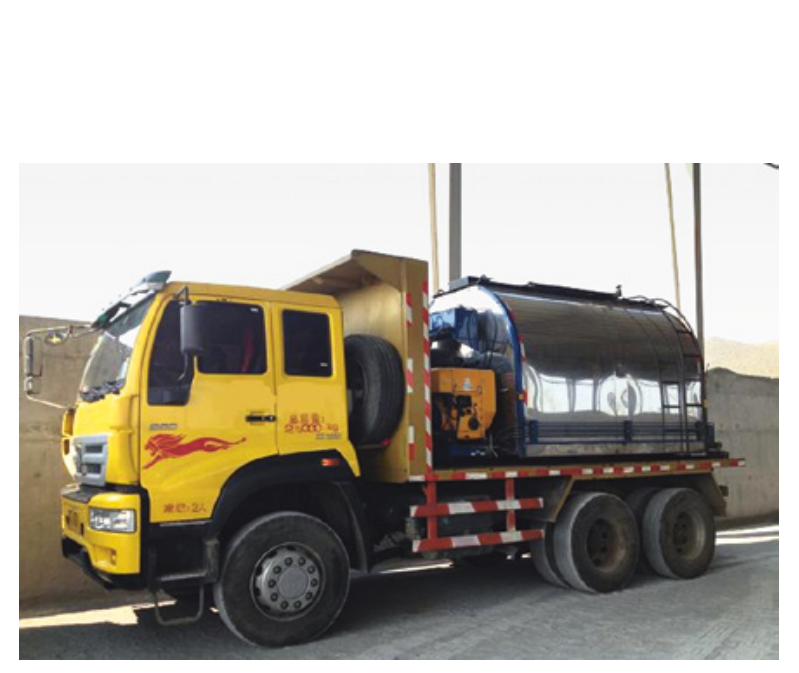

Figure 2. Mixing truck (Cooker)

batch plant and are mixed for about $2 \mathrm{~min}$. The mixtures are then dumped into the mixing truck (Figure 2) for secondary mixing and transportation. The MA used in the study was produced by the above two processes to illustrate the universal applicability of the research results.

\subsection{Laboratory testing}

To evaluate the rutting resistance at higher temperatures and the fatigue characteristics of the steel-bridge-deck asphalt mixtures, the laboratory-based testing program consisted of three types of tests: the Wheel-Tracking Test (WTT), the impact-loading test, and the four-point bending beam fatigue test.

\subsubsection{Wheel-Tracking Test}

Many test methods were used worldwide to evaluate the rutting resistance of asphalt mixtures (Guo \& Prozzi, 2006). In this study, a wheel-tracking device (Figure 3) was used to evaluate the hightemperature performance of various asphalt-concrete specimens, in according to Chinese Standard Test Method T0719 (JTG E20-2011 Standard Test Method of Bitumen and Bituminous Mixture for Highway Engineering). The Wheel-tracking test was developed by the Transport and Road Research Laboratory in Great Britain. This test was performed at a temperature of $60{ }^{\circ} \mathrm{C}$, with a loading speed of $42 \mathrm{times} / \mathrm{min}$ and a wheel-contact pressure of $0.7 \mathrm{MPa}$. Total-deformation values were measured on the specimen surface after it was subjected to $60 \mathrm{~min}$ of repeated wheel loading. Also recorded was the DS, defined in this test as the number of wheel loadings required to induce a $1 \mathrm{~mm}$ deformation during a testing timeframe of 45 min-60 min. 


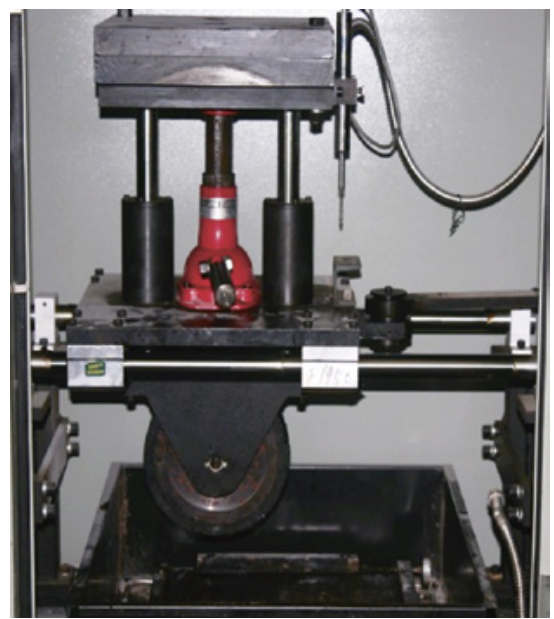

Figure 3. Wheel-tracking device

\subsubsection{Impact-Loading Test}

The Impact-Loading Test (ILT) was used to evaluate the fatigue characteristics of asphalt mixtures in a pavement system (Yu, 2005). In this test, asphalt concrete specimens made with different materials were compacted to the size $30.0 \times 30.0 \times 5.0 \mathrm{~cm}$, and the specimens were then cut into beams of size $25.0 \times 3.5 \times 3.5 \mathrm{~cm}$. After being cured in a water bath for 4 hours at a constant temperature of $15^{\circ} \mathrm{C}$, the beams were subjected to impact loading at a speed of $50 \mathrm{~mm} / \mathrm{min}$ (Figure 4).

Derived from a loading-displacement curve (Figure 5), the impact toughness parameter (represented by the area under the curve up to the

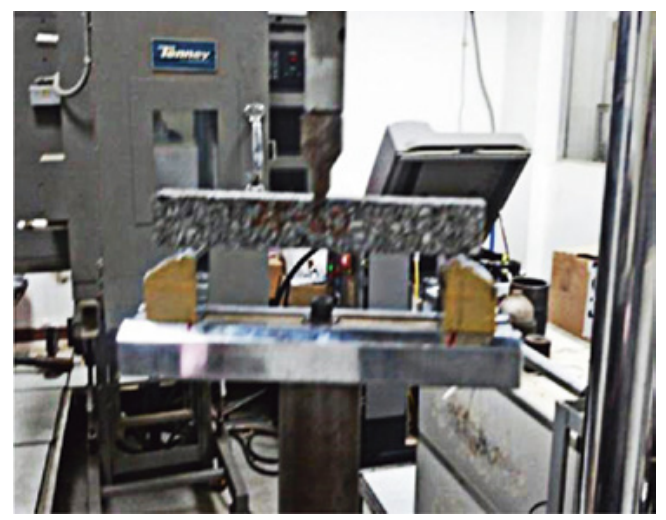

Figure 4. Impact-toughness test 


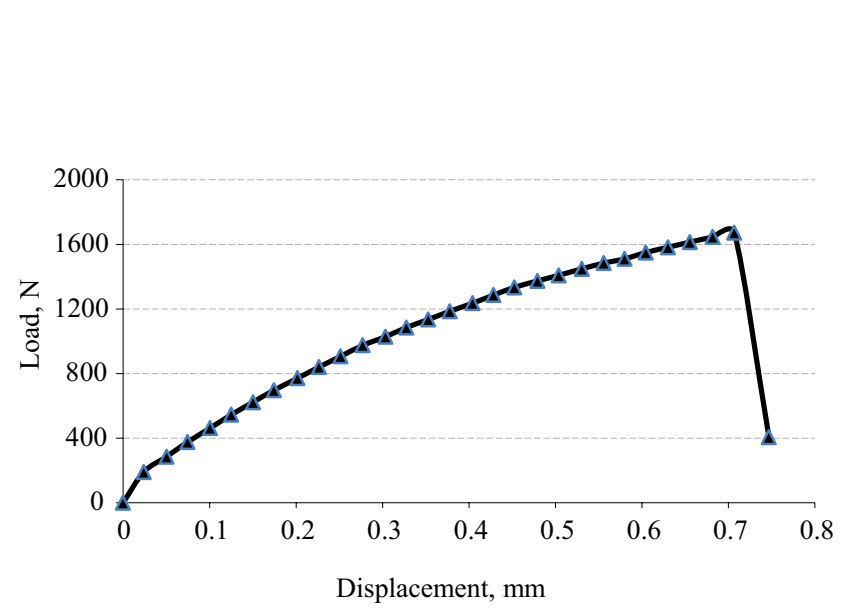

Figure 5. Loading-displacement curve

failure point), was used to characterise the fatigue capacity of the MA mixtures. The higher the impact toughness values of the materials, the better the ability to resist fatigue cracking.

For a single measurement, $a$, if

$$
\mid a \text {-average value of measurements } \mid \leq k \text { standard deviation, }
$$

where $k$ is $1.15,1.46,1.67$, or 1.82 if the number of specimens is $3,4,5$, or 6 , respectively.

If the measured data were determined to be valid, then the test result was equal to the average value. Otherwise, if measurement a was considered to be invalid, then it was removed from further analysis, and the test result was equal to the average value of the remaining data except for $a$.

Three kinds of devices for four-point bending fatigue test, provided by James Cox \& Sons, Cooper Research Technology, and Industrial Process Controls, were considered. Yu (2005) evaluated these three types of bending devices in a constant-strain test mode, and the fatigue-test results were the same. Figure 6 shows the Cooper Research Technology test apparatus was used in the study.

The size of the specimens was $381.00 \pm 6.35 \mathrm{~mm}$ (length) by $63.50 \pm$ $6.35 \mathrm{~mm}$ (width) by $50.80 \pm 6.35 \mathrm{~mm}$ (height), and the number of specimens ranged from three to six. Specimens were cured at a constant temperature for 4 hours and then were subjected to sinusoidal loading with a frequency of $10 \mathrm{~Hz}$ at $15.0 \pm 0.1^{\circ} \mathrm{C}$. The initial stiffness modulus was at the point where the MA modulus started to decrease. The number of loading cycles required to reach the critical damage point, defined as the modulus at $50 \%$, was the fatigue life of the MA mixtures. The same data-processing procedure as used in the ILT, was applied in assessing these fatigue-test data. 


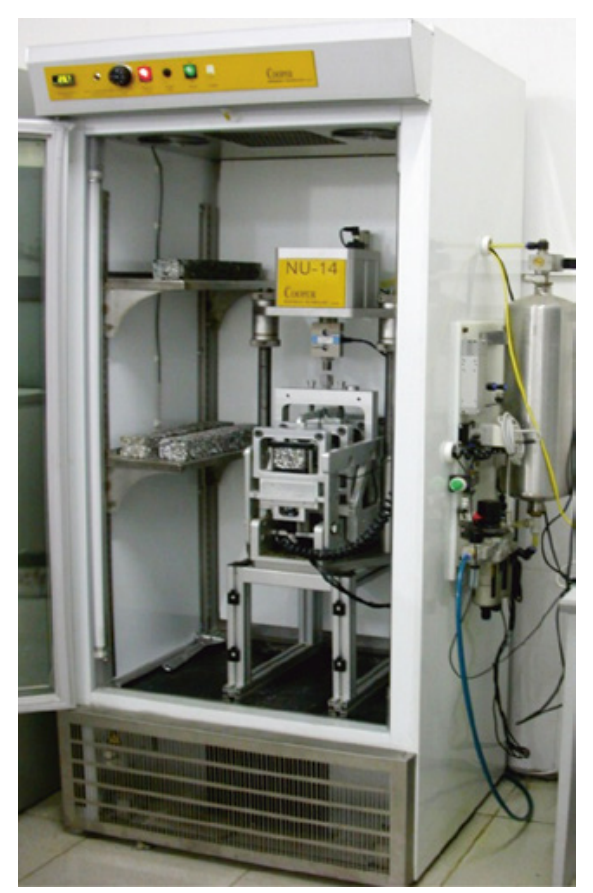

Figure 6. Four-point bending-beam fatigue test

\section{Results and discussion}

Specimens were prepared at various mixing temperatures for various mixing times. The prepared specimens were subjected to the four-point bending-beam fatigue testing at a strain level of $300 \mu \varepsilon$, and a constant temperature of $15^{\circ} \mathrm{C}$. Specimens were also prepared for ILT at various mixing temperatures. The test results and the calculated accumulated dissipative-energy values for the various mixes are presented in Table 4. The experimental results show that the mixing temperature and time affect the accumulated dissipative energy, fatigue life, and impact toughness. The longer the mixing time, the worse the MA fatigue properties. The higher the mixing temperature, the shorter the fatigue life. The short mixing time and low mixing temperature were beneficial to fatigue performance. 
Table 4. Results of four-point bending beam fatigue and impact-loading tests

\begin{tabular}{ccccc}
\hline $\begin{array}{c}\text { Mixing } \\
\text { equipment }\end{array}$ & $\begin{array}{c}\text { Mixing time } \\
\text { and } \\
\text { temperature }\end{array}$ & $\begin{array}{c}\text { Accumulated } \\
\text { dissipative } \\
\text { energy, } \\
\mathbf{M J} / \mathbf{m}^{3}\end{array}$ & $\begin{array}{c}\text { Fatigue life } \\
(\mathbf{3 0 0} \boldsymbol{\mu \varepsilon}) \\
\text { cycles }\end{array}$ & $\begin{array}{c}\text { Impact } \\
\text { toughness, } \\
\mathbf{N} \cdot \mathbf{m m}\end{array}$ \\
\hline $\mathrm{A}$ & $45 \mathrm{~min}, 195^{\circ} \mathrm{C}$ & 286.9 & 1546026 & 2154 \\
$B$ & $2 \mathrm{~h}, 210^{\circ} \mathrm{C}$ & 197.9 & 1329276 & 1697 \\
$\mathrm{~A}$ & $2 \mathrm{~h}, 205^{\circ} \mathrm{C}$ & 211.7 & 1074462 & 847 \\
$B$ & $4 \mathrm{~h}, 240^{\circ} \mathrm{C}$ & 137.1 & 831555 & 202 \\
$B$ & $1.5 \mathrm{~h}, 220^{\circ} \mathrm{C}$ & 335.8 & 1780029 & 2040 \\
$B$ & $2 \mathrm{~h}, 230^{\circ} \mathrm{C}$ & 189.9 & 886963 & 785 \\
$B$ & $3 \mathrm{~h}, 230^{\circ} \mathrm{C}$ & 163.8 & 702931 & 543 \\
$B$ & $4 \mathrm{~h}, 230^{\circ} \mathrm{C}$ & 145.9 & 778227 & 441 \\
$B$ & $5 \mathrm{~h}, 230^{\circ} \mathrm{C}$ & 122.4 & 719439 & 375 \\
\hline
\end{tabular}

Note: *A - using conventional mixing simulator, mixing time started when coarse was added to simulator and temperature reached the preset value; $B$ - mixtures were agitated for 2-3 minutes in the batch plant and then put into Cooker truck for additional mixing time.

\subsection{Dissipative energy and fatigue life}

When viscoelastic materials are subjected to cyclic loadings, the strain-stress curve is different under loading and unloading conditions but mutually connect, forming closed paths termed hysteresis loops. The area within each loop represents the loss of strain energy during each cycle of loading and unloading for a given constant load. For a viscoelastic material, such as the asphalt concrete mixture, the external work applied to the material is consumed in part by inducing cracking on the surface and in part by inducing flow deformation. In fatigue testing, separating the energy applied to cracking from the energy transformed to heat is difficult (in plastic deformation).

A typical strain-stress curve under cyclic loadings is shown in Figure 7.

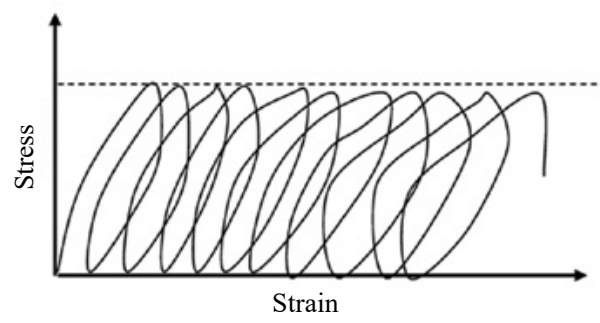

Figure 7. Strain-stress curve sketch
Guilian Zou, Xiaoning Zhang, Chung Wu

Experimental Method of Fatigue Performance of Mastic Asphalt for Bridge Deck Pavement 
Because of stress-strain hysteresis, when an asphalt-concrete specimen is subjected to cyclic sinusoidal loading

$$
\sigma(t)=\sigma_{0} \sin (\omega t),
$$

and the corresponding strain has the form

$$
\varepsilon(t)=\varepsilon_{0}[\sin (\omega t+\varnothing)],
$$

where $\varnothing$ is the phase or dispassion angle.

Then, letting

$$
x=\sigma_{0} \sin (\omega t) \text { and } y=\varepsilon_{0}[\sin (\omega t+\varnothing)]
$$

by mathematical transformation, the following Eq. (5) was derived to represent the stress-strain hysteresis curve under one loading cycle:

$$
\frac{\left(x-\frac{\sigma_{0}}{2}\right)^{2}}{\left(\frac{\sigma_{0}}{2}\right)^{2}}+\frac{\left(y-\frac{\varepsilon_{0}}{2}\right)^{2}}{\left(\frac{\varepsilon_{0}}{2}\right)^{2}}-\frac{8 \cos \varphi}{\sigma_{0} \varepsilon_{0}}\left(x-\frac{\sigma_{0}}{2}\right)\left(y-\frac{\varepsilon_{0}}{2}\right)=\sin ^{2} \varphi .
$$

For sinusoidal loading, the dispassion energy at the $i^{\text {th }}$ loading cycle was represented as

$$
\omega_{i}=\pi \sigma_{i} \varepsilon_{i} \sin \varphi_{i},
$$

where $\omega_{i}$ - dissipative energy in $i^{\text {th }}$ loading cycle; $\sigma_{i}$ - peak stress in $i^{\text {th }}$ loading cycle; $\varepsilon_{i}$ - peak strain in $i^{\text {th }}$ loading cycle; $\varphi_{i}$ - phase angle in $i^{\text {th }}$ loading cycle, for viscoelastic materials, $0<\varphi<\frac{\pi}{2}$.

During fatigue testing, the accumulated dissipative energy is the sum of all areas enclosed by all hysteresis loops. The total dissipative energy at the damage point was represented as

$$
W_{f}=\sum_{i=1}^{N_{f}} \omega_{i},
$$

where $N_{f}$ - fatigue life, cycle; $W_{f}$ - accumulated dissipative energy, $\mathrm{MJ} / \mathrm{m}^{3}$.

From their study on the characteristics of energy consumption of pavement specimens under fatigue loading, Van Dijk \& Visser (1977) proposed the following Eq. (8):

$$
W_{f}=A \cdot N_{f}^{Z},
$$

where $A$ and $Z$ are test constant. 


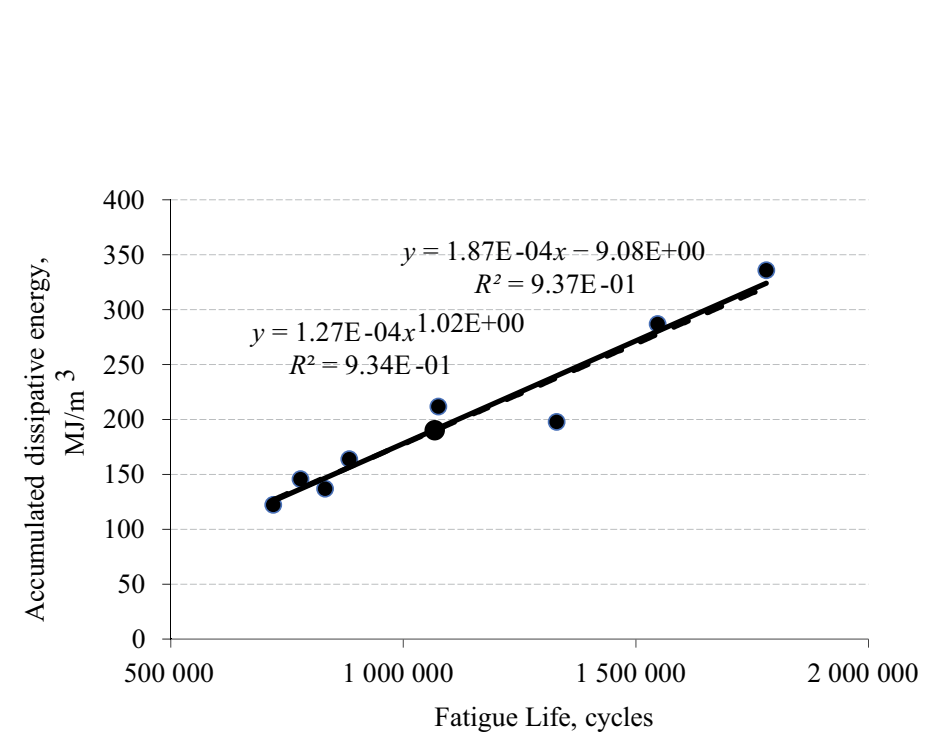

Figure 8. Relationship between fatigue life and accumulated dissipative energy

From Eq. (8), the fatigue damage occurs when cumulative energy consumption reaches a critical value. This phenomenon is known as the energy consumption criterion.

In the research, based on the 1977 study, the correlation between fatigue life and accumulated dissipative energy of the asphalt specimens was analysed (Figure 8).

Figure 8 shows the parameter $Z$ of the Eq. (8) is 1.02, that is close to 1. Therefore, the correlation between fatigue life and the accumulated dissipative energy is considered linear. Linear regression analysis (dashed line in Figure 8; coefficient of correlation $R^{2}=0.937$ ) indicates that higher required accumulated dissipative energy at the damage point of material corresponds to longer fatigue life.

\subsection{Impact toughness and accumulated dissipative energy}

On the plot of a typical loading-displacement curve (Figure 5), the impact-toughness parameter is represented by the area under the curve up to the failure point. Impact toughness was interpreted as the energy required fracturing the specimen under impact loading. As shown in Figure 9, the theoretically predicted relationship between impact toughness and accumulated dissipative energy was confirmed in the results of the four-point bending-beam fatigue testing (at $300 \mu \varepsilon$ ) that reveal the linear correlation $\left(R^{2}=0.82\right)$ observed for impact toughness (in $\mathrm{N} \cdot \mathrm{mm}$ ):

$$
\mathrm{I}=9.54 W_{f}-890.33
$$

where $I$ - impact toughness, $\mathrm{N} \cdot \mathrm{mm} ; W_{f}$ - accumulated dissipative energy.
Guilian Zou,

Experimental

Method of Fatigue

Performance

of Mastic Asphalt for Bridge Deck

Pavement 


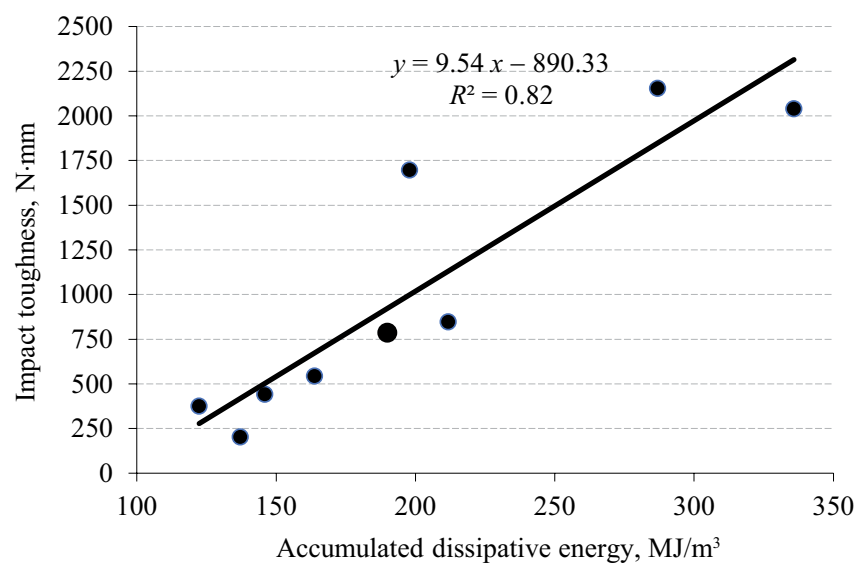

Figure 9. Relationship between impact toughness and accumulated dissipative energy

\subsection{Impact toughness and fatigue life}

The impact toughness test is a simple test that is easy to perform. As shown in Figure 10, the linear relationship between the impact toughness of the material and its fatigue life (obtained from four-point bending beam fatigue test) takes the following form:

$$
N_{f}=469.96 I+637833 \text {, }
$$

where $N_{f}$ - fatigue life, cycle; $I$ - impact toughness, N.mm; correlation coefficient $-R^{2}=0.922$.

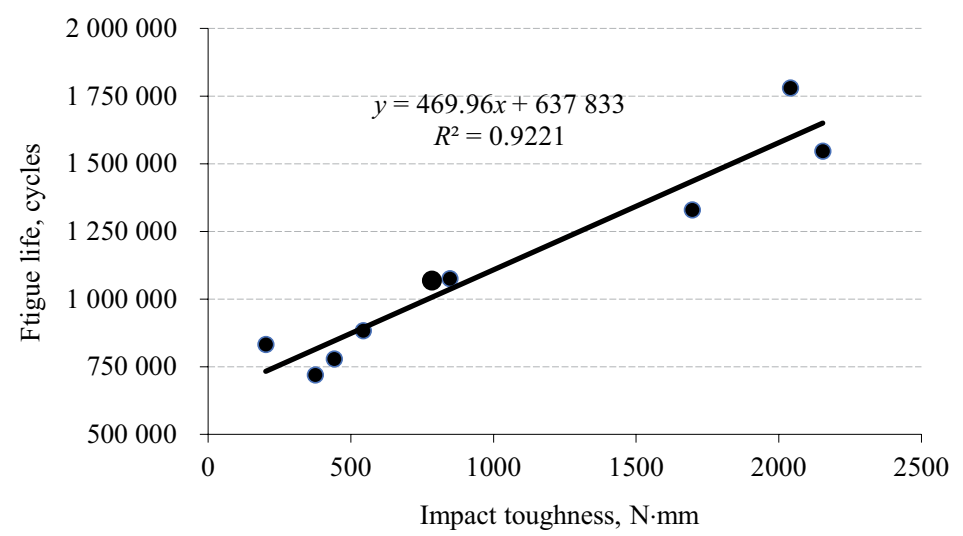

Figure 10. Relationship between impact toughness and fatigue life 
Because of the high correlation coefficient, impact toughness was recommended as a quality control measure during bridge deck construction and as a reference index during the mixture design process in the study.

\subsection{Rutting resistance and fatigue performance}

With increasing mixing time and mixing temperatures, the MA mixture continues to age, and DS increases, thus increasing the ability of the material to resist rutting. However, impact toughness decreases with ageing, thus reducing the fatigue life of the mixture. Therefore, balancing the performance requirements of the MA mixture between the rutting resistance and fatigue cracking is important.

Wheel-Tracking Tests were performed on MA specimens to evaluate the rutting resistance of the material, and DS values were recorded. Regression analysis was performed to evaluate the interrelationship of impact toughness and DS (Figure 11). The exponential function between these two indexes is an inverse relationship with a good correlation coefficient $\left(R^{2}=0.688\right)$. As impact toughness decreases, DS increases. Therefore, DS was used as the quality-control index during construction, and both a minimum and a maximum value are specified. When performing MA mixture design, materials selection, and construction control, both the impact toughness and DS were specified. The two indexes were used for quality control of the pavement project for the Hong Kong-Zhuhai-Macao Bridge; to ensure deformation

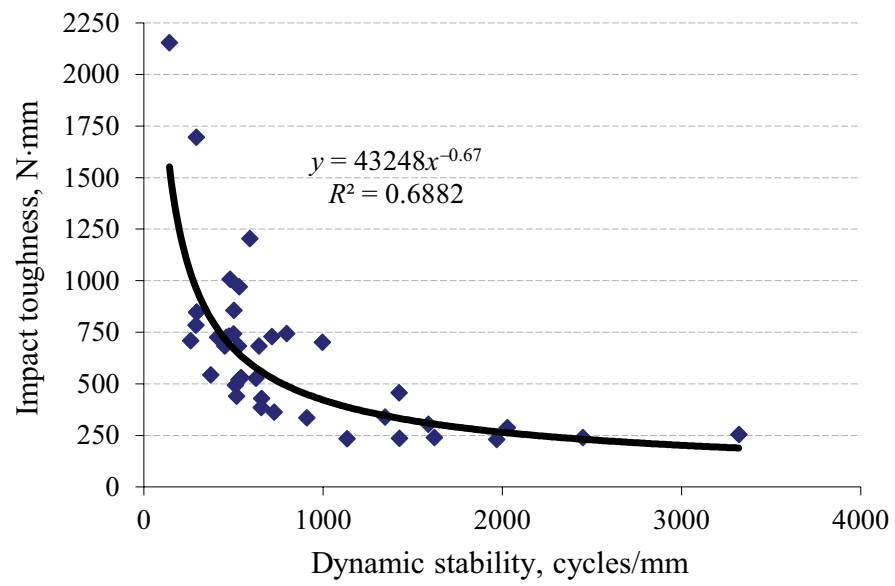

Figure 11. Relationship between impact toughness and dynamic stability for mastic asphalt
Experimental Method of Fatigue Performance of Mastic Asphalt for Bridge Deck Pavement 
resistance and fatigue performance of the bridge-deck pavement, the DS was required to be 300 800 cycles/mm and impact toughness no less than $400 \mathrm{~N} \cdot \mathrm{mm}$.

\section{Conclusions}

The following conclusions were drawn from this study:

1. The impact toughness parameter is derived based on the energy concept. It was regarded as the energy required to fracture specimens under impact loading. The results show that the relationship between impact toughness and cumulative dissipation energy is linear, the higher the cumulative dissipation energy of mastic asphalt is, the larger the impact toughness is, and correlation coefficient is 0.82 .

2. The results of four-point bending beam fatigue tests reveal a linear relationship between accumulated dissipative energy and fatigue life of the mastic asphalt mixtures. The higher the required accumulated dissipative energy is at the damage point, the longer the fatigue life of mastic asphalt mixture.

3. There was a linear relationship between impact toughness and fatigue life obtained by four-point bending beam test, and the correlation degree is very high. Impact toughness test has low requirements for testing equipment and short test period, so it is suitable for fatigue performance index for design and construction of mastic asphalt mixture for bridge deck pavement.

4. Impact toughness and dynamic stability were found to be inversely correlated. As impact toughness increases, dynamic stability decreases. Therefore, fatigue performance and rutting resistance are mutually restrictive properties of mastic asphalt. Based on the required performance balance, impact toughness and dynamic stability are recommend to be used for quality control in mastic asphalt design and pavement construction. It is recommended that the dynamic stability meet the requirement of $300 \sim 800$ cycles $/ \mathrm{mm}$ and impact toughness meet the requirements of greater than or equal to $400 \mathrm{~N} \cdot \mathrm{mm}$. Of course, it is appropriate to propose targeted index requirements for each specific project.

\section{Acknowledgements}

The authors gratefully acknowledge the financial support to the project by the National Science and Technology Program of China 
(No. 2011BAG07B03) and Dept of Transportation of Guandong Province (No. 2013-02-022 and No. 2013-03-018).

All researchers and technicians of Institute of Road Engineering in South China University of Technology and Guangdong Provincial ChangDa Highway Engineering CO. Ltd are gratefully acknowledged for their active assistance throughout this study.

\section{REFERENCES}

AASHTO T321-2007 Standard Method of Test for Determining the Fatigue Life of Compacted Hot-Mix Asphalt (HMA) Subjected to Repeated Flexural Bending

Battista, R. C., Pfeil, M. S., \& Carvalho, E. M. (2008). Fatigue life estimates for a slender orthotropic steel deck. Journal of Constructional Steel Research, 64(1), 134-143. https://doi.org/10.1016/j.jcsr.2007.03.002

BS EN 13108-6:2006 Bituminous Mixtures - Material Specifications - Part 6: Mastic Asphalt

BS 1447:1998 Specification for Mastic Asphalt (Limestone Fine Aggregate) for Roads, Footways and Pavings in Building

BS 812-103.2 Testing Aggregates - Part 103: Methods for Determination of Particle Size Distribution - Section 103.2: Sedimentation Test

Buirette, C., \& Huez, J. (2010). Impact toughness enhancement of an electron beam welded Ti-6Al-4V titanium alloy through post-welding heat treatment, The Minerals, Metals \& Materials Society 2010 -139th Annual Meeting and Exhibition, Seattle, WA, United States, vol.3, 593-600.

de Jong, F. (2006). Renovation techniques for fatigue cracked orthotropic steel bridge decks. PhD thesis, Delft University of Technology.

Dilthey, U., Lüder, F., Bleck, W., Langenberg, P., \& Nagel, M. (2001). Testing of the notch-impact toughness of laser-beam-welded joints. Welding Research Abroad, 47(4): 35-38.

Guo, R., \& Prozzi, J. (2006). Characterization of Hamburg wheel tracking device testing results. In Applications of Advanced Technology in Transportation (pp. 105-110). https://doi.org/10.1061/40799(213)18

Jeong, Y. S., Kainuma, S., \& Ahn, J. H. (2013). Structural response of orthotropic bridge deck depending on the corroded deck surface. Construction and Building Materials, 43, 87-97.

https://doi.org/10.1016/j.conbuildmat.2013.01.011

JTG E20-2011 Standard Test Method of Bitumen and Bituminous Mixture for Highway Engineering (in Chinese)

Kyung, K. S., Shin, D. H., Lee, H. H., \& Jeon, J. C. (2006). A suggestion of effective structural details for orthotropic steel deck, Proceedings of the 10th East Asia-Pacific Conference on Structure, Bangkok, Thailand, 547-552.

Liu, X., Medani, T. O., Scarpas, A., Huurman, M., \& Molenaar, A. A. A. (2010). Characterisation of surfacing materials for orthotropic steel deck bridges. Part 2: numerical work. International Journal of Pavement Engineering, 11(3), 255-265. https://doi.org/10.1080/10298430902859346 
Medani, T. O., Huurman, M., Liu, X. Y., Scarpas, A., \& Molenaar, A. A. A. (2007). Describing the behaviour of two asphaltic surfacing materials for orthotropic steel deck bridges. Advanced Characterisation of Pavement Soil Engineering Materials, 1\&2, 1351-1368.

Mull, M. A., Othman, A., \& Mohammad, L. (2005). Fatigue crack propagation analysis of chemically modified crumb rubber-asphalt mixtures. Journal of Elastomers \& Plastics, 37(1), 73-87. https://doi.org/10.1177/0095244305049898

Mull, M. A., Stuart, K., \& Yehia, A. (2002). Fracture resistance characterization of chemically modified crumb rubber asphalt pavement. Journal of Materials Science, 37(3), 557-566. https://doi.org/10.1023/A:1013721708572

Pinho, S. T., Robinson, P., \& Iannucci, L. (2006). Fracture toughness of the tensile and compressive fibre failure modes in laminated composites. Composites Science and Technology, 66(13), 2069-2079. https://doi.org/10.1016/j.compscitech.2005.12.023

Pouget, S., Sauzéat, C., Di Benedetto, H., \& Olard, F. (2010). Numerical simulation of the five-point bending test designed to study bituminous wearing courses on orthotropic steel bridge. Materials and Structures, 43(3), 319-330. https://doi.org/10.1617/s11527-009-9491-1

Shirahata, H., Akasaka, K., \& Iizuka, T. (2010). Detection of fatigue crack of steel deck plate by ultrasonic nondestructive testing, in Proceedings of the 5th International Conference on Bridge Maintenance, Safety and Management, Philadelphia, United States, 3537-3544. https://doi.org/10.2208/jscejseee.72.393

Tamminen, S., Juutilainen, I., \& Röning, J. (2010, July). Quantile regression model for impact toughness estimation. In Industrial Conference on Data Mining (pp. 263-276). Springer, Berlin, Heidelberg. https://doi.org/10.1007/978-3-642-14400-4_21

Van Dijk, W., \& Visser, W. (1977). The energy approach to failure for pavement design. Journal of the Association of Asphalt Paving Technologists, 46, 1-40.

Wang, M., Zhang, H., Zhu, M., Hao, Z., \& Xue, X. (2011). Research on structure and properties of embedded Gussasphalt. In Road Pavement and Material Characterization, Modeling, and Maintenance (pp. 106-114). https://doi.org/10.1061/47624(403)14

Way, G. B., Kaloush, K. E., Sousa, J. M. B., \& Zareh, A. (2009, September). Arizona's 15 years of experience using the four point bending beam test. In Second Workshop on Four-point Bending, Guimarães, Portugal (pp. 24-25).

Wu, W. J. (2009). Study on the Fatigue Performance of Gussasphalt Concrete [D]. Chongqing: Chongqing University.

Yu, J. M. (2005). Fatigue performance of asphalt-aggregate mixes (Doctoral dissertation, South China University of Technology).

Yu, J., \& Zhang, X. (2011). Comparisons of three types of four-point-bending fatigue testing machines for asphalt mixture. Road Machinery \& Construction Mechanization, 01, 79-82. (in Chinese)

Zou, G., Wu, C., \& Xu, J. (2013). Development of an experimental method for asphalt concrete overlay reflective cracking evaluation. International Journal of Pavement Research and Technology, 6(4), 327.

https://doi.org/10.6135/ijprt.org.tw/2013.6(4).327 